\title{
Análise e transposição didática de notícias sobre efeito estufa: desenvolvimento da habilidade leitora a partir dos preceitos de Charaudeau
}

\author{
Renata Ribeiro Guimarães \\ IFRJ - Campus Paracambi
}

\begin{abstract}
Resumo
Este artigo apresenta a transposição didática de notícias sobre efeito estufa, publicadas em inglês, analisadas a partir dos preceitos de Charaudeau (2010). A atividade didática se mostra pertinente para alunos de Inglês para Fins Específicos de áreas relacionadas às Ciências da Natureza para que possam agir social, profissional e academicamente no mundo.
\end{abstract}

Palavras-chave: notícias, transposição didática, inglês para fins específicos.

\begin{abstract}
This article presents the didactic transposition of news about the greenhouse effect, published in English, with an analysis based on Charaudeau's (2010) principles. The activity proves to be relevant to students of English for Specific Purposes in the Natural Sciences areas, and it should help them develop an ability to act socially, professionally and academically in the world.
\end{abstract}

Keywords: news, didactic transposition, English for Specific Purposes

\section{INTRODUÇÃO}

A partir de um trabalho de análise de necessidades, realizado com alunos cursando Licenciatura em Química, os resultados apontaram, dentre outros, que o gênero "notícia" e o tema "efeito estufa" são considerados relevantes para esse curso e áreas das Ciências da Natureza e afins. Visto isso, optamos por analisar esse gênero discursivo de ampla circulação e que abrange outros saberes, além do saber técnico e laboratorial, de modo a incentivar o letramento crítico. Durante a busca por esse tema largamente discutido na química e áreas afins, por meio de notícias, encontramos nos textos utilizados a análise a ser apresentada. As notícias foram publicadas em 27 de março de 2012 ou datas aproximadas, e abordam o tema "efeito estufa".

A proposta deste trabalho é analisar quatro textos (notícias) sobre o mesmo fato (acontecimento), publicados no mesmo dia (ou em datas bem próximas), à luz da teoria de Patrick Charaudeau, discutida no capítulo A construção da notícia: um mundo filtrado de seu 
livro Discurso das Mídias (2010). Para isso, a fundamentação teórica abordará algumas conceituações de gêneros discursivos e os principais pontos levantados por Charaudeau no capítulo em questão, para que sirvam como base para a análise do corpus escolhido.

Além disso, como forma de aplicabilidade, proporemos a transposição didática das notícias analisadas segundo a perspectiva de Charaudeau, e outros pontos que podem ser considerados relevantes no gênero, mas que não foram abordados pelo autor. Para isso, serão elaboradas atividades que têm como objetivo o desenvolvimento da habilidade leitora e criticidade, bem como do agir linguageiro dos alunos de áreas relacionadas às Ciências da Natureza e afins, na disciplina "Inglês para Fins Específicos".

\section{FUNDAMENTAÇÃO TEÓRICA}

Antes de abordarmos a visão de Charaudeau sobre notícia, faz-se necessário conceituar gêneros discursivos. Em seguida, apresentaremos uma breve revisão dos pontos abordados pelo semiolinguista em seu livro.

\section{Gêneros Discursivos}

Segundo Bakhtin, "cada enunciado particular é individual, mas cada campo de utilização da língua elabora seus tipos relativamente estáveis de enunciados, os quais denominamos gêneros do discurso" (2003, p. 262). Tal definição é corroborada por Marcuschi (2003) ao caracterizar gêneros como "eventos textuais altamente maleáveis, dinâmicos e plásticos" (p. 19).

Assim como Martin (2000), que postula que as culturas podem ser consideradas um sistema de gêneros e não existem sem eles, Marcuschi (2003) os conceitua como "entidades sociodiscursivas e formas de ação social incontornáveis em qualquer situação comunicativa" (p. 19), inserindo assim o caráter cultural na abordagem dos gêneros, pois estes devem ser "contemplados em seus usos e condicionamentos sociopragmáticos caracterizados como práticas sociodiscursivas" (p. 20).

Finalmente, Swales (1990), ao caracterizar gêneros como eventos comunicativos com propósitos compartilhados pelos membros de um determinado grupo, contribui para a compreensão de que esses enunciados relativamente estáveis se caracterizam "muito mais por suas funções comunicativas, cognitivas e institucionais do que por suas peculiaridades linguísticas e estruturais.” (MARCUSCHI, 2003, p.20) 


\section{O Gênero "Notícia"}

Charaudeau (2010) preconiza que o acontecimento nunca é transmitido em sua forma bruta, pois toda realidade empírica passa pelo filtro do ponto de vista particular. Segundo Costa (2009), "as aparências são o universo da notícia. Não basta que seja verdadeira. Ela deve parecer verdadeira." (COSTA, 2009, p. 159). Sendo assim, a notícia é a transmissão de um real construído, não da própria realidade, e é a partir desse ponto de vista que Charaudeau vai defender a construção da notícia como um mundo filtrado.

Partindo do princípio que o acontecimento só se torna notícia quando é levado ao conhecimento de outrem, Charaudeau propõe uma definição para notícia: "um conjunto de informações que se relaciona a um mesmo espaço temático, tendo um caráter de novidade, e proveniente de uma determinada fonte e podendo ser diversamente tratado." (CHARAUDEAU, 2010, p. 132).

Segundo o autor, a construção da notícia levanta três questões essenciais: "quais são os princípios de seleção dos fatos? Quais são os modos do recorte midiático do espaço social? Como são identificadas as fontes?" (CHARAUDEAU, 2010, p. 132). Desse ponto em diante, recorreremos às demais páginas do capítulo referente ao gênero "notícia" para responder a tais questionamentos.

\section{Os Princípios de Seleção dos Fatos}

Para que um acontecimento seja convertido em notícia, três aspectos são fundamentais para as escolhas efetuadas pela instância midiática: o tempo, o espaço social e a hierarquia dos fatos.

Acerca do tempo, podemos destacar a necessidade do fator "atualidade", pois é o que dá à notícia "seu caráter factual desprovido, em seu princípio, de qualquer qualificação subjetiva e de qualquer tentativa de explicação de sua razão de ser" (CHARAUDEAU, 2010, p. 133). A noção de atualidade é basicamente o guia das escolhas temáticas, juntamente com a efemeridade e a a-historicidade. O que contribui para uma notícia se tornar efềmera é a necessidade de constante inclusão de um elemento novo que seja portador de uma forte carga de inesperado. Já com relação ao caráter a-histórico da notícia, ele se dá por meio da referência frequente ao presente, e pouca menção ao passado ou futuro. Tudo isso contribui para uma visão superficial na abordagem dos acontecimentos, mas essa superficialidade é "blefada" pela narrativa. Segundo Charaudeau (2010), “o acontecimento é convertido em notícia através do processo narrativo que o insere numa interrogação sobre a origem e o devir, conferindo-lhe uma aparência (ilusória) de espessura temporal” (p. 135). 
O espaço social se constrói na tensão entre a ubiquidade e a proximidade não só na origem, mas no tratamento do acontecimento. $\mathrm{O}$ afastamento espacial do acontecimento é solucionado com a utilização de agências de informação, correspondentes, fontes oficiais ou oficiosas, e demais testemunhas. Assim, a instância midiática pode transmitir o acontecimento quase em tempo real, conferindo à instância de recepção (leitor, telespectador etc) a ilusão de estar em contato com fatos de diversas partes do mundo ao mesmo tempo. Por outro lado, a proximidade espacial pode proporcionar consequências paradoxais, pois ao mesmo tempo em que pode interessar muito àqueles que buscam informações locais, regionais ou, até mesmo, nacionais, pode ser pouco interessante àqueles que priorizam o que acontece ao redor do mundo. Tudo depende do modo como o acontecimento é tratado (com proximidade ou distanciamento), levando em consideração o antagonismo dos dois imaginários no qual o ser humano está inserido: a aldeia e o planeta. Aquele diz respeito ao homem que se apega ao que lhe é próximo, ao que é possível tocar ou reconhecer como familiar; este se refere aos que perseguem uma busca sem fim, buscam permanentemente os mundos e abrem o horizonte da vida. Aquele é alvo da imprensa nacional, enquanto este é almejado pela imprensa regional (CHARAUDEAU, 2010).

Finalmente, podemos falar dos critérios de importância na hierarquia dos acontecimentos, que são divididos em externos e internos. Os critérios externos se relacionam ao modo como o acontecimento aparece: surge de uma factualidade, é programado pela existência de um calendário, ou é suscitado porque é preparado ou provocado por um setor institucional. Já os critérios internos são aqueles relacionados às escolhas que a instância midiática opera. São eles: os critérios de proximidade espacial e temporal, e outros que os superpõem ou substituem, que podem ser explicados pela hipótese do agenda setting - a instância receptora organiza seus comentários a partir dos acontecimentos que mídia expõe. Dessa forma, diz-se que a instância midiática determinaria, de maneira impositiva, as informações às quais os leitores, por exemplo, teriam acesso naquele dia. Em outras palavras, o acontecimento é selecionado, percebido, reconhecido e tratado de maneira a ser consumido (filtragem), o que torna difícil a avaliação do seu impacto.

Podemos citar um acidente como um dos aspectos que são considerados relevantes e dos quais as mídias "tiram proveito" para evocar os dramas do destino do homem, são eles: o insólito, o enorme, o misterioso, o receptivo, o acaso, o trágico e o horror. Essas categorias demonstram um estado de desordem e outro de ordem social: características que colocam as mídias em contradição. A partir dessas categorias e características, podemos destacar a 
exclusão dos acontecimentos que fazem parte do cotidiano social e daqueles que se residem na distância histórica.

\section{Os Modos de Recorte Midiático do Espaço Social}

O recorte operado pelas mídias acontece em sua origem - busca e seleção do acontecimento e estruturação do espaço - e em seu término - operações de distribuição de rubricas e de repartições temáticas. Acerca disso, Charaudeau postula que "a estruturação do espaço social depende da instância fornecedora de informação que é obrigada a construir seu propósito gerenciando a visibilidade pública dos acontecimentos de que trata." (CHARAUDEAU, 2010, p. 143) Assim, as mídias devem estabelecer uma repartição para o espaço público, onde os acontecimentos são apresentados para serem consumidos ("domínios de atividade") e, também, a "natureza dos atores" que dela são parte. Esses domínios se referem à interação realizada por meio das práticas sociais e suas representações. Podemos citar três domínios de atividade: o domínio da atividade política, cujo foco é a vida, atos e propósitos dos responsáveis políticos; o domínio da atividade cidadã, que se concentra em abordar atos de reivindicação, protestos, palavras de cidadãos contra os poderes públicos; e $o$ domínio da atividade civil cotidiana, o qual envolve atores-testemunhas que passaram por experiências de heróis ou vítimas. Quanto à visibilidade dos atores sociais, podemos dizer que os critérios intencionam ora a credibilidade, ora a captação. A credibilidade é perseguida por meio de critérios de notoriedade e de representatividade; já a captação é relativa aos critérios de expressão e de polêmica.

As operações de distribuição de rubricas competem à instância midiática e correspondem às categorias de pensamento da instância receptora: informação relacionada à política nacional e internacional, informação econômica, social, cultural, esportiva, cotidiana etc. Essas rubricas dizem respeito à maneira como cada organismo estrutura seu espaço social, como a notícia é construída para ser consumida.

\section{A Identificação das Fontes}

A instância midiática lança mão de fontes ou externas ou internas para obter informações para construção das notícias. As internas são "internas aos organismos de informação" ou "externas a eles"; e as fontes externas são classificadas em "institucional" ou “não institucional”. O quadro abaixo (CHARAUDEAU, 2010, p. 148) resume as fontes que são utilizadas: 


\begin{tabular}{|c|c|c|c|}
\hline \multicolumn{4}{|c|}{$\begin{array}{c}\text { Figura } 4 \\
\text { A identificação das fontes }\end{array}$} \\
\hline \multicolumn{2}{|c|}{ "INT. MíDIAS" } & \multicolumn{2}{|c|}{ "EXT. MíDIAS" } \\
\hline $\begin{array}{l}\text { "int. org. info" } \\
\text { - Correspondentes } \\
\text { - Enviados especiais } \\
\text { - Arquivos próprios }\end{array}$ & $\begin{array}{l}\text { "ext. org. info" } \\
\text { • Agências e } \\
\text { indústrias de serviço } \\
\text { • Outras mídias }\end{array}$ & $\begin{array}{c}\text { "institucional" } \\
\text { (oficiais/oficiosas) } \\
\text { - Estado-Governo } \\
\text { - Administraçōes } \\
\text { • Org. sociais } \\
\text { (partidos, sindicatos) } \\
\text { • Políticos } \\
\text { (representantes sociais) }\end{array}$ & $\begin{array}{l}\text { "não institucional" } \\
\text { • Testemunhas } \\
\text { • Especialistas } \\
\text { • Representantes } \\
\text { (corpos profissionais) }\end{array}$ \\
\hline
\end{tabular}

É responsabilidade das mídias verificar e apresentar as fontes. Para apresentá-las, é necessário, além de fornecer a origem e os meios de identificar os signatários, escolher um modo de denominação e uma modalidade de enunciação que indique a relação entre a mídia e a fonte. O modo de denominação consiste em identificar a fonte através do nome, do título, da função ou por uma denominação vaga (i.e. "de fonte bem informada" etc); já a modalidade de enunciação pode ser expressa por verbos de modalidade (dizer, declarar etc), por locuções (“de acordo com”, "segundo" etc) ou pelo emprego do condicional (que indicam distância em relação ao valor da informação fornecida). Esses fatores influenciam na credibilidade da notícia, produzindo efeitos diversos: efeito de evidência quando a fonte não é citada; efeito de verdade e seriedade profissional se a fonte é identificada; e efeito de suspeita, se a identificação se faz de maneira vaga, anônima ou indireta.

\section{METODOLOGIA}

Faremos aqui uma breve descrição da metodologia adotada neste trabalho. Após a apresentação da teoria de Charaudeau acerca da construção da notícia, analisaremos o corpus seguindo a mesma linha de raciocínio: os princípios de seleção dos fatos, os modos de recorte midiático do espaço social e a identificação das fontes. Além disso, iniciaremos apresentando informações sobre os sites e, ao final da análise, retornaremos a eles para verificar que características das notícias corroboram as visões, missões ou informações sobre os sites.

Na seção seguinte, realizaremos a transposição didática da análise das quatro notícias, visando abordar os itens considerados importantes por Charaudeau e outros que não foram apontados por ele, mas são importantes para o desenvolvimento da habilidade leitora crítica 
nos sujeitos da pesquisa e a atuação nos contextos acadêmico, profissional e social por meio do gênero "notícia".

\section{ANÁLISE DAS NOTÍCIAS SOBRE EFEITO ESTUFA}

O assunto das notícias é a proposta do governo americano de, pela primeira vez na história do país, estabelecer uma regulamentação para limitar a quantidade de gases de efeito estufa que pode ser emitida por usinas elétricas na atmosfera. A lei, contudo, visa às companhias novas, aquelas que ainda estão sendo planejadas.

Para realizar a análise do acontecimento e a construção da notícia por diferentes organismos da instância midiática, optamos por abordar aqui quatro notícias obtidas em fontes diferentes, respectivamente: Global Warming is Real, Bloomberg, Washington Post e The Guardian. E para começarmos a análise, já com uma visão crítica do modo como a notícia pode ter sido construída pelos sites, buscamos informações sobre os mesmos - por exemplo, nas seções "about us" ou "our mission" dos organismos midiáticos.

Sobre a primeira fonte, é relevante destacar os seguintes trechos:

Global warming, environmental stewardship, the energy economy, and creating a sustainable future are the issues of our times. What we do as a civilization today will affect our progeny for generations to come. Global Warming is Real is published to help raise awareness of the reality before us.

The content offered here is meant to educate, enlighten, perhaps enrage, and maybe even entertain. If it gets you thinking seriously about global warming and sustainability, then we've done our job.

O site do Bloomberg oferece as seguintes informações:

Bloomberg connects influential decision makers to a dynamic network of information, people and ideas. Our strength - quickly and accurately delivering data, news and analytics through innovative technology - is at the core of everything we do. With over 15,000 employees in 192 locations, we deliver business and financial information, news and insight around the world.

Por outro lado, o Washington Post não oferece uma seção exclusiva para esse tipo de informação. Por isso, acessamos o site Washington Post Company, que declara que

Washingtonpost.com is a one-stop news, information and entertainment resource that helps users make sense of Washington, the Web and the world. The site offers something for everyone interested in what's happening in Washington.

Por fim, o que a página da Wikipedia diz sobre o The Guardian é:

The paper identifies with centre-left liberalism and its readership is generally on the mainstream left of British political opinion. It is also influential in design and publishing arena, sponsoring many awards in these areas. 
Dando continuidade à nossa análise, e tendo em mente a "intenção" de cada organismo da instância midiática, como podemos ponderar a seleção dos fatos para a conversão de acontecimento em notícia? Que possíveis recortes midiáticos foram feitos no espaço social em questão? O que as fontes identificadas (ou não) nos textos dizem sobre eles? Falaremos primeiro das características que os textos têm em comum e, caso haja diferenças, elas serão identificadas na sequência.

A partir das características do princípio do tempo na seleção de fatos, podemos destacar a noção de atualidade, e se compararmos as notícias deste trabalho com uma que foi publicada no dia anterior pelo Washington Post, notaremos a efemeridade do acontecimento, pois o elemento novo já era aguardado: "EPA to impose first greenhouse gas limits on power plants". Visto isso, é relevante verificar a importância da manchete no anúncio dos acontecimentos. Nas manchetes dos textos com os quais estamos trabalhando aqui, isso fica bastante evidente, pois algo que era esperado passa a ser verdadeiro e atual no momento da publicação. Observemos que, de acordo com os verbos em destaque, a manchete foi construída no simple present, o que colabora para a esse caráter de atualidade, a-historicidade: "Breaking News: EPA Issues First Limits on Greenhouse Gas Emissions for Power Plants", "EPA Introduces First Greenhouse-Gas Limits for Power Plants", "EPA imposes first greenhouse gas limits on new power plants" e "Obama plan cuts emissions for future coal plants".

Quanto ao espaço social, como foi dito, identificamos que é construído entre a proximidade e ubiquidade. Assim, é interessante verificar que as três primeiras trazem a EPA em suas manchetes e no corpo do texto, visto que são fontes americanas e essa agência é de amplo conhecimento nacional; já a notícia do The Guardian, jornal britânico, primeiro fala-se de Obama ou "the Obama administration", para depois falar de "Environmental Protection Agency" e, somente na segunda metade da notícia, a sigla EPA é utilizada. Podemos notar esse último como uma tentativa da fonte britânica de aproximar o leitor, caso não conheça a sigla. No que diz respeito à intenção de tornar a notícia como pertinente para o mundo em geral, destacamos uma frase utilizada pelos sites Global Warming is Real e Bloomberg que é uma citação do diretor de política climática da Federação Nacional da Vida Selvagem: "The EPA is taking a big step toward protecting the world our children will inherit." E a citação usada por três das fontes, exceto Bloomberg, que menciona a "proteção do planeta para nossas crianças". A partir disso, podemos inferir que pessoas de outros países também podem se interessar pela notícia, pois a proteção do planeta está sendo colocada em questão. 
Em se tratando da hierarquia dos acontecimentos, há de se concordar que a importância da notícia se dá por diversos aspectos. Podemos destacar o fato de ter sido um acontecimento programado para terça-feira, dia 27 de março de 2012, e por ter sido preparado pelo poder público: a Agência de Proteção Ambiental e a administração do Presidente Obama. Outro fator importante é que o que antes causava desordem - a emissão desregrada de gases que contribuem para o efeito estufa e o aquecimento global - agora é motivo de comemoração pelo triunfo da ordem - lei que praticamente impossibilita qualquer outra companhia que polui de ser aberta nos EUA.

O valor da construção do espaço social é percebido no recorte midiático feito pelos sites a partir de um acontecimento que faz parte do domínio da atividade política. A credibilidade da notícia é "conquistada" a partir da menção de pessoas com um alto grau de notoriedade e representatividade nesse contexto - o Presidente Barack Obama; Lisa Jackson, a chefe da EPA; o diretor de política climática da Federação Nacional da Vida Selvagem, Joe Mendelson etc. A captação, por outro lado, foi "conquistada" por meio da polêmica criada ao mostrarem opiniões adversas à nova lei - principalmente de Republicanos e Democratas, de grupos industriais e apoiadores das empresas fornecedoras de energia. Finalmente, o recorte é formalizado por meio das rubricas e seções. Visto que a informação é relacionada à política nacional americana, mas também tem importância econômica e ambiental, e até mesmo mundial, observemos as rubricas dadas por cada organismo da instância midiática: Global Warming is Real - EarthTalk, Environmental Resources, Bloomberg: Personal Finance, WashingtonPost: Health and Science e TheGuardian: Environment. Notamos aqui que há uma grande divergência entre as visões do Bloomberg e as demais fontes.

Passemos agora à identificação das fontes utilizadas pela instância midiática. Com exceção do The Guardian, não foram encontradas fontes internas aos demais organismos de informação. A razão para isso pode estar no fato de o acontecimento ser de amplo conhecimento, por já estar sendo anunciado havia algum tempo. O jornal britânico cita Suzanne Goldenberg, intitulada como US environment correspondent. A notícia retirada do Global Warmingis Real sugere outras fontes e leituras: Bloomberg e The Washington Post, que são outras mídias que também foram abordadas aqui, externas àquele organismo midiático. É preciso, todavia, ressaltar que o site ambientalista se preocupou em mostrar a visão favorável à ação do governo em prol do meio ambiente. O fato de haverem sugerido as demais fontes pode ser uma forma de amenizar essa abordagem parcial.

No que diz respeito às fontes de informação externas às mídias, observamos que o foco foi dado às fontes institucionais (sejam elas a favor ou contra a tal lei): "the Obama 
administration", "EPA", "Energy Information Agency", "National Wildlife Federation", "U.S. Global Change Research Program", "the Republicans", "the Democrats", "Coal-state lawmakers", "Edison Electric Institute", "Center for Clean Air Policy”, "Clean Air Watch" etc. Além dessas, todos os organismos citaram também fontes não-institucionais, com exceção do site ambientalista, a saber: "energy analysts", "advocacy groups", “industry groups", "Scott Segal, a lobbyist for the power providers", "environmental groups" etc.

Para concluir, como o site Global Warming is Real visa a conscientização da população acerca da realidade do planeta, principalmente no que diz respeito ao meio ambiente, algumas escolhas midiáticas realizadas se mostram coerentes ao objetivo, como, por exemplo, o fato de não citarem fontes de informação não-favoráveis à política de Obama. O Bloomberg, que se destaca em termos de informação financeira e de negócios, localizou a notícia sob a rubrica de "finanças pessoais", as quais realmente podem ser afetadas com a nova política. Já o The Washington Post, por ser focado em informar todos aqueles que se interessam pelo que se passa em Washington, realizou bem o seu objetivo, visto que, no dia anterior, havia publicado uma notícia criando expectativa não só regional, mas nacional. $\mathrm{O}$ "estrangeiro" The Guardian, por ser um jornal de grandes influências para a esquerda Britânica, optou por uma abordagem bem "radical" do fato. É o único que usa termos como "nearly impossible" e "effectively blocked" para tratar da dificuldade que será para construir novas usinas, dados os novos padrões estabelecidos; o jornal usa também "disappointment" para descrever o sentimento dos grupos envolvidos em relação ao fato de as companhias já estabelecidas ficarem de fora da nova lei.

\section{TRANSPOSIÇÃO DIDÁTICA}

Partindo do princípio que a transposição didática (CHEVALLARD, 1991) visa à transferência do saber científico para o saber escolar, esta seção apresentará uma atividade didática que aborda os pontos de análise expostos na seção anterior. Além de apresentar as atividades, faremos a descrição de cada exercício para tornar a leitura mais fluida. Os objetivos são: levar os alunos a compreenderem o gênero "notícia", bem como sua construção, por meio de exercícios baseados na teoria de Charaudeau (2010); levá-los também a lerem e entenderem quatro notícias sobre o mesmo tema/assunto. Vale ainda ressaltar que os textos completos fazem parte do anexo da atividade didática quando entregue aos alunos.

Propomos iniciar com uma atividade de conscientização sobre o gênero "notícia", de modo a familiarizar os alunos acerca dos textos que eles vão ler. 
1. Discuta com um colega o que vocês entendem sobre "notícias". Em seguida, leia o conceito do gênero "notícia" abaixo e complete usando palavras apropriadas.

A notícia é um formato de divulgação de um __ por meios jornalísticos. É a matéria-prima do Jornalismo, normalmente reconhecida como algum dado ou socialmente relevante que merece publicação numa mídia. Fatos sociais, culturais, naturais e outros podem ser notícia se afetarem indivíduos ou grupos significativos para um determinado veículo de imprensa. Grande parte das vezes, a notícia pode ter conotações diferenciadas, justamente por ser excepcional, anormal ou de grande impacto social, como tragédias, guerras e Notícias têm valor jornalístico apenas quando acabaram de ou quando não foram noticiadas previamente por nenhum veículo. Nem

todo texto jornalístico é noticioso, mas toda notícia é potencialmente objeto de apuração jornalística.

[Retirado do artigo "O gênero "notícia”: uma proposta de análise e intervenção" de Maria Virginia Brevilheri Benassi (PG UEL). Disponível em: http://www.ple.uem.br/3celli_anais/trabalhos/estudos_linguisticos/pfd_linguisticos/069.pdfAcessado em 30/05/2012.]

Em seguida, podemos escolher o texto do The Washington Post, por exemplo, para o reconhecimento dos seguintes itens: tema, assunto, data de publicação, autor e público-alvo.

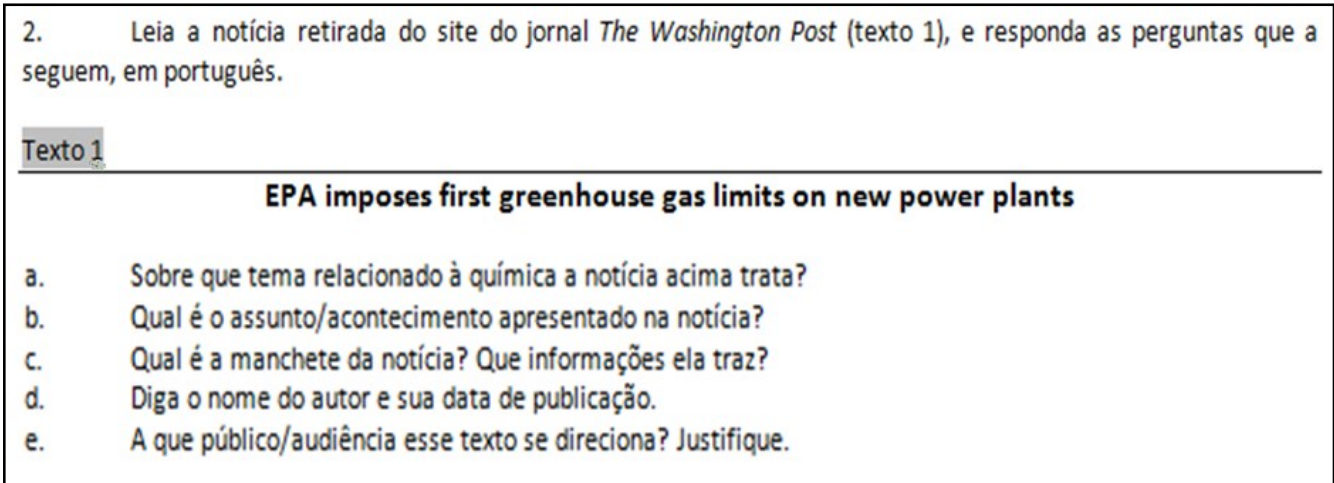

Para fins de comparação, é válido apresentarmos agora a notícia do site Global Warming is Real, e sugerir que os alunos verifiquem semelhanças e diferenças entre as notícias, principalmente, em relação ao público-alvo.

3. Agora, leia outra notícia, esta retirada do site Global Warming is Real, e responda os mesmos itens do exercício 2 baseando-se no texto abaixo. Caso haja outra característica que seja interessante para abordar na comparação, faça-o também.

Texto 2

Breaking News: EPA Issues First Limits on Greenhouse Gas Emissions for Power Plants 
Após a realização da previsão acerca do público-alvo, podemos abordar as informações sobre os sites, para que os alunos identifiquem os pontos de concordâncias entre a visão da organização midiática e a forma como a notícia foi construída.

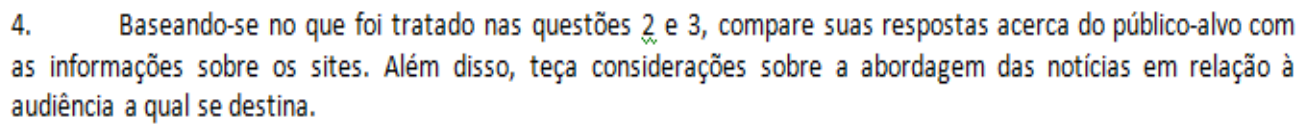

Washingtonpost.com is a one-stop news, information and entertainment resource that helps users make sense of Washington, the Web and the world. The site offers something for everyone interested in what's happening in Washington.

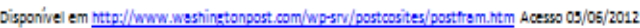

Global warming, environmental stewardship, the energy economy, and creating a sustainable future are the issues of our times. What we do as a civilization today will affect our progeny for generations to come. Global Warming is Real is published to help raise awareness of the reality before us. The content offered here is meant to educate, enlighten, perhaps enrage, and maybe even entertain. If it gets you thinking seriously about global warming and sustainability, then we've done our job.

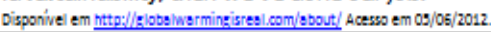

Começando agora com alguns pontos abordados por Charaudeau, iniciamos com a questão do tempo.

5. Uma característica importante de uma notícia é que ela tem que passar a noção de atualidade, presente. Analise quatro manchetes sobre 0 acontecimento tratado aqui (duas você já conhece, e as outras duas foram tiradas dos sites Bloomberg e The Guardian), e diga que aspecto linguístico está relacionado com essa característica. Justifique sua resposta. (OBS: Os textos completos estão anexados à folha de atividades.)

"EPA imposes first greenhouse gas limits on new power plants" (The Woshington Post)

"Breaking News: EDA lssues First Limits on Greenhouse Gas Emissions for Power Plants" (Globol Worming is Real)

"EPA Introduces First Greenhouse-Gas Limits for Power Plants" (Bloomberg) "Obama plan cuts emissions for future coal plants". (The Guordion)

Visto que as manchetes foram apresentadas anteriormente, seria fundamental introduzir informações sobre os demais sites e levar os alunos a inferirem quais seções (rubricas) são escolhidas pelos sites para rotular as notícias. 
6. $\quad$ Ainda baseando-se nas manchetes, levante hipóteses sobre em que seção dos sites as notícias foram alocadas. Justifique sua resposta levando em consideração as informações sobre os sites. Os trechos abaixo serão úteis:

Bloomberg connects influential decision makers to a dynamic network of information, people and ideas. Our strength - quickly and accurately delivering data, news and analytics through innovative technology - is at the core of everything we do. With over 15,000 employees in 192 locations, we deliver business and financial information, news and insight around the world. Disponivel em nttp://www. bloomberg.com/companj/ameny Acesso em 05/06/2012

The paper identifies with centre-left liberalism and its readership is generally on the mainstream left of British political opinion. It is also influential in design and publishing arena, sponsoring many awards in these areas.

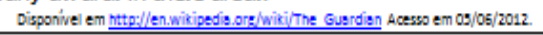

Considerando os conceitos de ubiquidade, proximidade e outros, relacionados às fontes de informação, é importante que os alunos conheçam alguns news values. Também, aproveitando o gancho das fontes, faz-se necessário abordar a questão da credibilidade da notícia e captação de leitores.

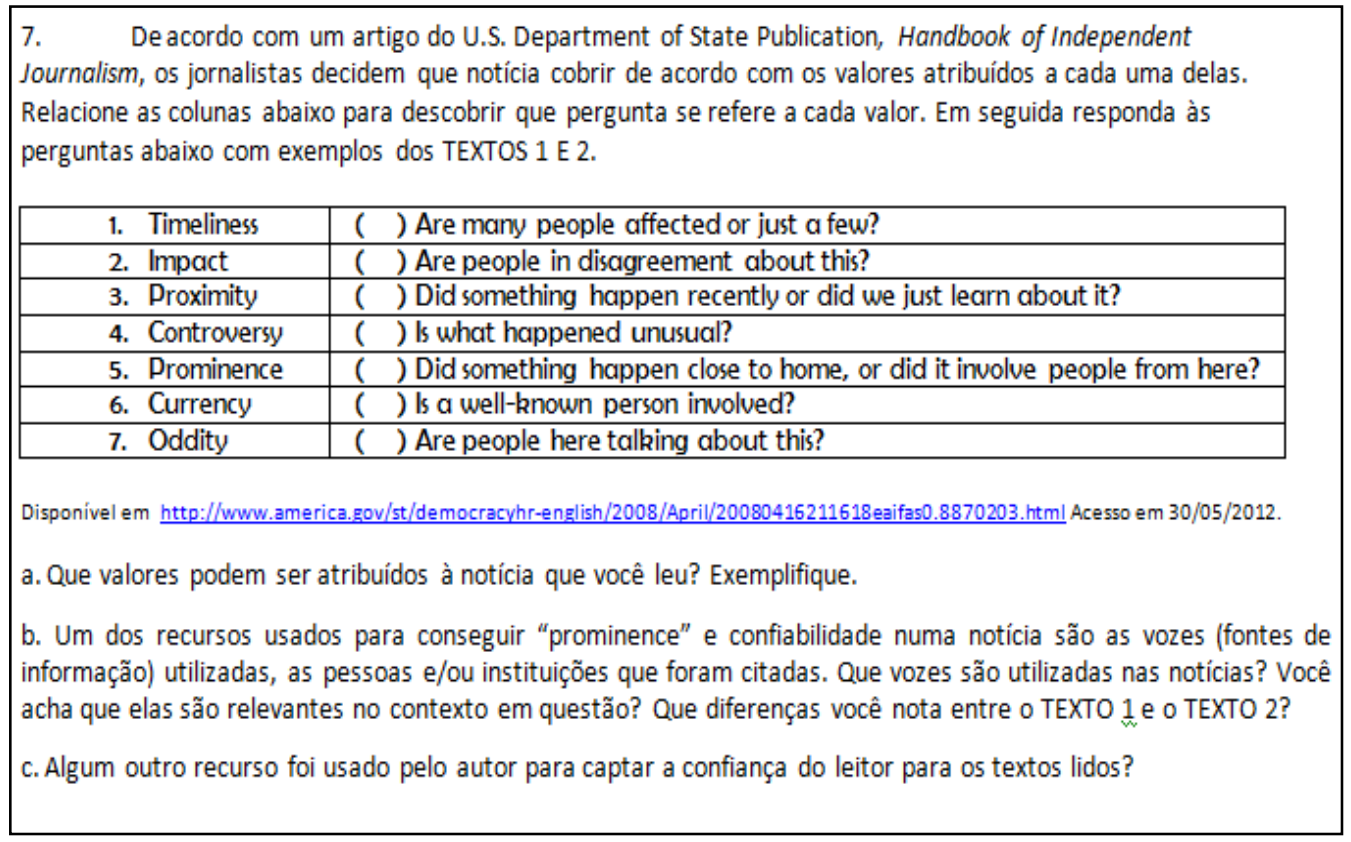

O próximo exercício intenciona levar os alunos a lerem outros dois textos (as notícias dos sites Bloomberg e The Guardian) para que eles possam compará-los com os dois primeiros e destacar as similaridades e diferenças quanto aos itens de análise trazidos nos exercícios anteriores. 
8. Agora, leia os dois outros textos (em anexo) e compare com os TEXTOS 1 e 2. Em seguida, aponte similaridades e diferenças no que diz respeito aos: a) aspectos linguísticos; b) fontes de informação (vozes) mencionadas; c) outros recursos utilizados para conquistar a confiança da audiência e dar credibilidade à notícia.

Finalmente, visando a levar os alunos a refletirem criticamente acerca do processo de seleção dos fatos midiáticos e do acontecimento aqui tratado, a última questão levanta o questionamento sobre a novidade, o incomum.

9. Para concluir, comente acerca de uma citação de John Bogart (1918): "When a dog bites a man, that is not news, because it happens so often. But if a man bites a dog, that is news." Utilize exemplos das notícias lidas para justificar sua resposta.

\section{CONSIDERAÇÕES FINAIS}

Além das razões pedagógicas que sinalizam a importância do trabalho com notícias em sala de aula, por ser um gênero discursivo relevante para os alunos atuarem social, acadêmica e profissionalmente, não como mero pretexto para o ensino de língua em sala de aula, podemos destacar também o incentivo à leitura crítica dados os passos de construção do acontecimento midiático.

Para finalizar o trabalho aqui apresentado, é de extrema importância destacar que em momento algum pretendemos esgotar os pontos de análise do semiolinguista Patrick Charaudeau ou atingir a exaustão do gênero "notícia". Por exemplo, o blefe da narrativa e o triunfo da ordem sobre a desordem não foram explicitamente transpostos nessa atividade didática. Por outro lado, os aspectos linguísticos característicos de uma notícia foram trabalhados em alguns exercícios.

\section{REFERÊNCIAS}

BAKHTIN, M. Os gêneros do discurso. In: . Estética da criação verbal. São Paulo: Martins Fontes, 2003.

BENASSI, M. V.B. O gênero "notícia": uma proposta de análise e intervenção. In: Anais do CELLI - Colóquio de Estudos Linguísticos e Literários. v. 3, 2007, Maringá: UEL, 2009, pp. 
$<$ http://www.ple.uem.br/3celli_anais/trabalhos/estudos_linguisticos/pfd_linguisticos/069.pdf $>$ Acesso em 30/05/2012.

CHARAUDEAU, P. A construção da notícia: um mundo filtrado. In: Discurso das Mídias. 2 ed. São Paulo: Editora Contexto, 2010, pp. 131 - 151.

CHEVALLARD, Y. La Transpostion Didactique - du savoir savant au savoir enseigné. La Pensée Sauvage Éditions. Grenoble, 1991.

COSTA, S. R. Dicionário de gêneros textuais. 2 ed. rev. ampl. Belo Horizonte: Autêntica Editora, 2009.

MARCUSCHI, L.A. Gêneros textuais: definição e funcionalidade. In: DIONISIO, A. P. et al (Orgs.) Gêneros textuais e ensino. Rio de Janeiro: Lucerna, 2003, p. 19 - 36

MARTIN, J.R. Grammar meets genre: reflections on the Sydney School. Inaugural Lecture at Sydney University Arts Association, 2000. Disponível em <http://linguistlist.org $>$ Acesso em dezembro de 2012.

SWALES, J.M. Genre analysis - English in academic and research settings. Cambridge University Press, 1990.

\section{Sites de Notícias:}

BLOOMBERG, 2012. Disponível em: <http://www.bloomberg.com/news/2012-03-27/epaissues-first-greenhouse-gas-limit-for-u-s-power-plants-1-.html> Acesso em: 10/05/2012.

GLOBAL WARMING IS REAL, 2012. Disponível em: <http://globalwarmingisreal.com/ 2012/03/27/breaking-news-epa-issues-first-limits-on-greenhouse-gas-emissions-for-powerplants> Acesso em: 10/05/2012.

THE GUARDIAN, 2012. Disponível em: <http://www.guardian.co.uk/environment/2012/ mar/27/coal-obama-coal-emissions-environment?INTCMP=SRCH $>$ Acesso em: 10/05/2012.

THE WASHINGTON POST, 2012. Disponível em: $<$ http://www.washingtonpost.com/national/health-science/epa-to-impose-first-greenhousegas-limits-on-power-plants/2012/03/27/gIQAKdaJeS_story.html>Acesso em: 10/05/2012.

\section{A AUTORA}

Renata Ribeiro Guimarães é professora de Inglês para Fins Específicos no IFRJ - Campus Paracambi; mestre em Estudos de Linguagem pela UFF; especialista em Linguística Aplicada: Ensino de Inglês como Língua Estrangeira pela UFF, e Tradução (Inglês) pela UGF; graduada em Licenciatura Plena e Bacharelado em Letras (Inglês e Literaturas) pela UERJ. Interesses de estudo e pesquisa: Linguística Aplicada, Ensino de Inglês como Língua Estrangeira, Livros Didáticos, Gêneros Discursivos, Inglês para Fins Específicos.

E-mail: renata.guimaraes@gmail.com 